\title{
中国太行山东麓 $\mathrm{NO}_{X}$ 重污染成因分析
}

\author{
田贺忠 ${ }^{(1)}$ ，王艳 ${ }^{(1)}$ ，赵丹 ${ }^{(1)}$ ，柴发合 ${ }^{(2)}$, 邢子山 ${ }^{(3)}$, 程轫 ${ }^{(1)}$ \\ (1) 北京师范大学环境学院, 环境模拟与污染控制国家重点实验室, 北京 100875 ; \\ (2) 中国环境科学研究院, 北京 100012; \\ (3) 北京邮电大学计算机科学与技术学院, 北京 100876 \\ E-mail: hztian@bnu.edu.cn
}

2010-11-13 收稿, 2011-04-01 接受

国家自然科学基金资助项目(20677005, 40975061)

\begin{abstract}
摘要 采用 $\mathrm{OMI} /$ Aura 对流层 $\mathrm{NO}_{2}$ 柱浓度产品, 分析研究了中国太行山东麓(ESTM)地区 $\mathrm{NO}_{X}$ 污染的季节变化特征. 研究结果表明, $\mathrm{NO}_{2}$ 柱浓度夏季最低而冬季最高. 为了探讨该地区 $\mathrm{NO}_{2}$ 重污染的成因, 本研究采用第五代 NCAR/Penn State 中尺度模式(MM5)对该地区风场进行模拟. MM5 模式模拟结果显示, 该地区的主导风向主要为东北风和西北风, 其次为西南风. 冬季代表 月 $\left(2007\right.$ 年 1 月) 中, 高 $\mathrm{NO}_{2}$ 浓度 (大于 $50 \times 10^{15} \mathrm{molec} / \mathrm{cm}^{2}$ ) 主要发生在以下 3 种风场类型: 辐合风 场 (5 天), 东北风(2 天), 静风(1 天)。尽管与其他发达地区相比, 该地区人为源 $\mathrm{NO}_{X}$ 的排放强度 相对较小, 但辐合风类型的频繁发生, 以及不利于扩散的地形条件, 导致了大气污染物的不断 积聚, 从而形成高 $\mathrm{NO}_{X}$ 污染区. 此外, 当主导风向为东北风时, 特别是输送气流风速较大时, 可 明显观察到从北京-天津-唐山地区向下风向 ESTM 地区的长距离传输影响.

关键词

太行山东麓

遥感观测

卫星数据

对流层 $\mathrm{NO}_{2}$

污染

风场

中国
\end{abstract}

近年来，随着以煤炭为主能源消费量的不断增 加, 以及汽车保有量和行驶里程的迅速增长, 中国伴 随 $\mathrm{NO}_{X}$ 排放产生的一次和二次大气污染问题在世界 范围内得到了广泛关注 ${ }^{[1 \sim 4]}$. 目前, 社会关注和国家 研究的焦点和热点主要是东部经济高速发展地区的 $\mathrm{NO}_{X}$ 重污染问题, 如长江三角洲(YRD)地区, 珠江三 角洲(PRD)地区, 京津冀地区等 ${ }^{[5 \sim 8]}$. 然而, 研究中我 们发现, 虽然与其他经济发达地区相比, 太行山东麓 地区人为源 $\mathrm{NO}_{X}$ 的排放量相对较小 ${ }^{[9]}$, 但该地区大气 中 $\mathrm{NO}_{2}$ 的浓度却很高, 已成为我国新的 $\mathrm{NO}_{X}$ 重污染 区. 目前, $\mathrm{NO}_{X}$ 的排放及污染防治工作已提上日程, 并被列为中国“十二五”环境保护工作的重点. 因此, 探讨 $\mathrm{NO}_{X}$ 重污染区的成因并提出有效的控制对策具 有十分重要的意义. 本研究采用 2007 年全年的 OMI/Aura 对流层 $\mathrm{NO}_{2}$ 柱浓度产品, 分析了太行山东 麓地区 $\mathrm{NO}_{X}$ 污染的季节变化特征. 并借助第五代 NCAR/Penn State 中尺度气象模式 MM5(v3.7), 开展
了区域气象场的数值模拟, 探究中国太行山东麓地 区 $\mathrm{NO}_{2}$ 高浓度形成的原因.

\section{1 方法及数据来源}

( i ) OMI 卫星 $\mathrm{NO}_{2}$ 监测资料. OMI(Ozone Monitoring Instrument)探测仪, 是搭载在 EOS AURA 卫星上的紫外光纤光谱仪. Aura 卫星于 2004 年 7 月 发射升空, 大约在当地时间 13:45 通过赤道. OMI 覆 盖全球只需 1 天时间, 空间分辨率可达 $24 \mathrm{~km} \times 13 \mathrm{~km}$. 总的来看, 与其他探测器相比, OMI 具有较高的空间 分辨率和更低的监测干扰. 总柱浓度和对流层 $\mathrm{NO}_{2}$ 柱浓度的反演运算法则详见文献[10].

$\mathrm{NO}_{2}$ 通常被用来作为 $\mathrm{NO}_{X}$ 反应产物的代表物. 本研究中采用 DOMINO (Dutch OMI $\mathrm{NO}_{2}$ ) v1.02 对流 层 $\mathrm{NO}_{2}$ 柱浓度产品, 并将其插值到水平分辨率为 $0.5^{\circ} \times 0.5^{\circ}$ 的网格中. 由于其较高的时空分辨率, OMI 卫星探测数据被广泛应用于监测 $\mathrm{NO}_{X}$ 浓度的变化情

英文版见: Tian H Z, Wang Y, Zhao D, et al. Formation and causes of $\mathrm{NO}_{X}$ pollution on the east side of the Taihang Mountains in China. Chinese Sci Bull, 2011, 56, doi: 10.1007/s11434-011-4518-8 
况 ${ }^{[6,11,12]}$ 、评价控制措施 ${ }^{[13,14]}$ 以及改善 $\mathrm{NO}_{X}$ 源排放清 单等 ${ }^{[15]}$. 低层大气中的 $\mathrm{NO}_{X}$ 主要来源于地面源的排 放 ${ }^{[16]}, \mathrm{OMI} \mathrm{NO}_{2}$ 柱浓度可以捕捉地面 $\mathrm{NO}_{2}$ 浓度的差 异, 能够很好地反映地表 $\mathrm{NO}_{2}$ 浓度的分布情况 ${ }^{[17,18]}$.

为了考察 OMI 卫星数据的可靠性和有效性, 许 多学者将 $\mathrm{OMI} \mathrm{NO}$ 柱浓度与地基遥感测量数据 ${ }^{[19,20]}$, 飞机航测数据 ${ }^{[21,22]}$, 及地基 $\mathrm{NO}_{2}$ 观测数据 ${ }^{[18,23 ~ 25]}$ 进 行了比对. 研究结果表明, 偏差较小, $\mathrm{OMI} \mathrm{NO}_{2}$ 适用 于区域空气质量的分析研究.

(ii) 气象场模拟. MM5 模式参数设置如表 1 所示. 模拟时段与 OMI 卫星观测数据一致, 为 2007 年 1 12 月, 每月连续运行. 模式采用 3 层嵌套, 第 1 层包含 $55 \times 48$ 个网格, 分辨率为 $81 \mathrm{~km} \times 81 \mathrm{~km}$, 涵盖 了中国大部分地区以及朝鲜半岛和日本列岛. 第 2 层 包含 $79 \times 61$ 个网格, 分辨率为 $27 \mathrm{~km} \times 27 \mathrm{~km}$, 涵盖了 中国的中部和东部地区. 第 3 层含 $79 \times 82$ 个网格, 分 辨率为 $9 \mathrm{~km} \times 9 \mathrm{~km}$, 涵盖了京津冀及其周边地区和太 行山东麓地区(ESTM). 垂直分辨率为 23 层. NCEP FNL 全球再分析数据来源于美国国家大气研究中心 (NCAR)计算机和信息系统实验室 (CISL, http://dss. ucar.edu/datazone/dsszone/ds083.2/index.html?g=1), 分 辨率为 $1.0^{\circ} \times 1.0^{\circ}$, 每 6 小时 1 个, 一日 4 次.

\section{ESTM 地区 $\mathrm{NO}_{X}$ 污染的季节变化特征}

研究中, 将 3 5 月份定义为春季, 6 8 月为夏季,

表 1 MM5 模式参数设置

\begin{tabular}{|c|c|}
\hline 参数 & 设置 \\
\hline 模拟时间 & 2007 年 $1 \sim 12$ 月 \\
\hline 输出结果 & 逐时 \\
\hline \multirow[t]{2}{*}{ 中心点 } & $33.8^{\circ} \mathrm{N}, 115^{\circ} \mathrm{E}$ \\
\hline & $55 \times 48$ (格距 $81 \mathrm{~km})$ \\
\hline \multirow[t]{2}{*}{ 水平网格 } & $79 \times 61$ (格距 27 km) \\
\hline & 79 × 82 (格距 9 km) \\
\hline 垂直分辨率 & 23 层 \\
\hline 地形数据 & USGS 30"数据 \\
\hline 土地利用数据 & USGS 25 类 30 "数据 \\
\hline 再分析数据 & NCEP FNL 全球再分析数据 \\
\hline 积云参数化方案 & Grell \\
\hline 显示水汽方案 & 简单冰相 \\
\hline 大气辐射方案 & 云辐射 \\
\hline 边界层参数化方案 & MRF \\
\hline 表面过程 & 5 层土壤模式 \\
\hline 嵌套 & 双向嵌套 \\
\hline
\end{tabular}

9 11 月为秋季, 12 次年 2 月为冬季. 将 2007 年 $\mathrm{NO}_{2}$ 柱浓度水平划分为 8 个等级, 并绘制成 $0.5^{\circ} \times 0.5^{\circ}$ 网格 分布图. 由图 1 可见, $\mathrm{NO}_{2}$ 重污染区主要分布在我国 的东部地区.

以往的研究表明，由于经济活动水平、能源消耗 量、发展水平、人口密度等不同，中国 $\mathrm{NO}_{2}$ 的排放量 分布地区差异明显 ${ }^{[26]}$. $\mathrm{NO}_{2}$ 排放主要集中在我国的人 口和工业化中心一一东部和南部沿海省份, 如山东、 广东、浙江、江苏等. 总体来看, 中国 $\mathrm{NO}_{2}$ 污染严重 的高值区主要有以下 4 个：长江三角洲地区、珠江三 角洲地区、京津冀地区和四川盆地, 如图 2 所示 ${ }^{[9]}$.

然而, OMI 观测的 $\mathrm{NO}_{2}$ 浓度高值区有 5 个, 并可 划分为以下 2 种类型: (1) 高 $\mathrm{NO}_{X}$ 排放强度对应 $\mathrm{NO}_{2}$ 高浓度, 包括长江三角洲地区、珠江三角洲地区、 京津冀地区和四川盆地; (2) $\mathrm{NO}_{X}$ 排放强度相对较小, 而 $\mathrm{NO}_{2}$ 浓度却很高, 主要为太行山东麓地区. 在过 去的几年中，该地区已成为我国 $\mathrm{NO}_{2}$ 柱浓度最高的 地区，主要涵盖河北、山西、河南等省份的边界交 界处.

大气中 $\mathrm{NO}_{X}$ 浓度季节变化的影响因素众多, 如 排放强度的变化、大气中 $\mathrm{NO}_{X}$ 的生命周期、大气环 流等等. 图 1 给出了 $\mathrm{OMI}$ 对流层 $\mathrm{NO}_{2}$ 柱浓度的季节 变化特征. $\mathrm{NO}_{2}$ 浓度的最低值出现在夏季, 这与夏季 垂直混合作用较强、光化学反应和降雨对 $\mathrm{NO}_{2}$ 的去 除作用较强有关. $\mathrm{NO}_{2}$ 浓度的最高值出现在冬季. 此 外，与我国南部省份和地区相比, ESTM 地区不同季 节 $\mathrm{NO}_{2}$ 污染变化幅度更为显著. 在我国南部的省份 和地区, $\mathrm{OMI} \mathrm{NO}_{2}$ 柱浓度的季节变化主要是由不同季 节大气中 $\mathrm{NO}_{X}$ 的生命周期和损失率变化造成的. 而 在 ESTM 地区, 冬季 $\mathrm{NO}_{2}$ 污染的加剧可能主要源于 商业和家庭燃煤供暖造成的 $\mathrm{NO}_{X}$ 排放量增加.

已有研究显示, 除排放外, 还有诸多因素影响区 域环境空气中 $\mathrm{NO}_{X}$ 的污染水平, 如地形、风向等 ${ }^{[27,28]}$ 因此, 本研究采用 MM5 模式探究太行山东麓 $\mathrm{NO}_{2}$ 重污染区可能的污染成因.

\section{ESTM 地区 $\mathrm{NO}_{X}$ 重污染成因分析}

\section{1 不利的地形条件}

为探讨 ESTM 地区 $\mathrm{NO}_{2}$ 重污染可能的成因, 采 用 MM5 模式模拟、输出了 ESTM 地区的日均气象场. 

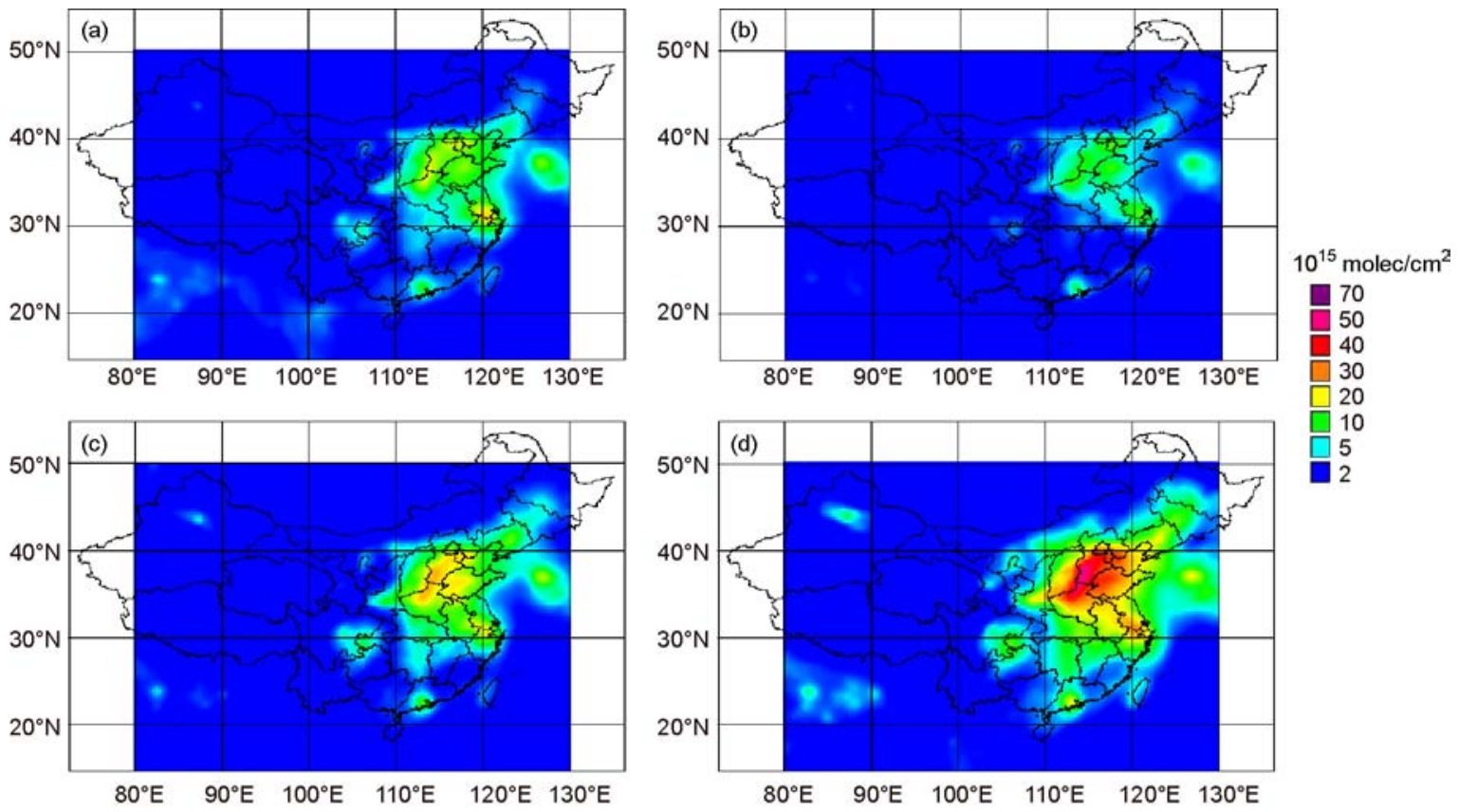

图 12007 年 $\mathrm{OMI}$ 对流层 $\mathrm{NO}_{2}$ 柱浓度四季日均值分布

(a) 春季; (b) 夏季; (c) 秋季; (d) 冬季

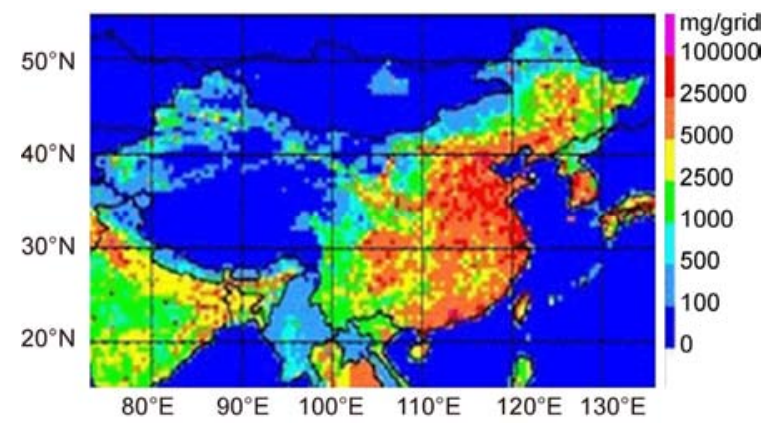

图 22006 年中国 $\mathrm{NO}_{X}$ 排放量分布(引自文献[9])

图 3 为 2007 年各季节代表月份 (1, 4, 7 和 10 月)近地 面流场示意图. 从图 3 中可以看到, 由于西侧太行 山脉阻挡作用, 太行山东麓地区存在一个全年各季 节风速均较小的地区，极不利于大气污染物的扩散 稀释.

\section{2 风向}

表 2 给出了 2007 年太行山东麓地区近地面风场 的季节变化特征. 在该区域, 全年主导风向为东北风 和西北风, 其次为西南风. 由于地形条件限制, 该地 区很少出现西风. 2007 年全年, 静风共出现 34 天, 且
表 2 ESTM 地区近地面风场的季节变化特征

\begin{tabular}{crrrr}
\hline \multirow{2}{*}{ 风向 } & \multicolumn{4}{c}{ 天数 } \\
\cline { 2 - 5 } & 春季 & 夏季 & 秋季 & 冬季 \\
\hline $\mathrm{NE}$ & 19 & 15 & 21 & 12 \\
$\mathrm{NW}$ & 18 & 9 & 13 & 26 \\
$\mathrm{SE}$ & 3 & 28 & 1 & 2 \\
$\mathrm{SW}$ & 24 & 6 & 12 & 13 \\
$\mathrm{E}$ & 5 & 12 & 0 & 1 \\
$\mathrm{~N}$ & 3 & 3 & 10 & 5 \\
$\mathrm{~S}$ & 6 & 7 & 11 & 7 \\
$\mathrm{C}$ & 2 & 6 & 15 & 11 \\
辐合风 & 12 & 6 & 8 & 13 \\
\hline
\end{tabular}

主要发生在秋季和冬季. 在静风的情况下, 大气污染 物更容易发生积聚, 继而加重污染. 此外, 表 2 中还 给出了一种特殊的风场类型, 一般出现在春季和冬 季, 这里称其为辐合风场.

如图 4 所示, 在辐合风型控制下, 有 2 条重要的 输送气流同时影响太行山东麓地区. 其中一条为东 北气流, 控制研究区域的北部地区, 另一条为西南气 流, 控制太行山东麓的南部地区. 由于它们的辐合作 用, 出现了一个风速相对较小的中间过渡区域. 这种 气流的辐合作用将大气污染物输送至研究区域，而 

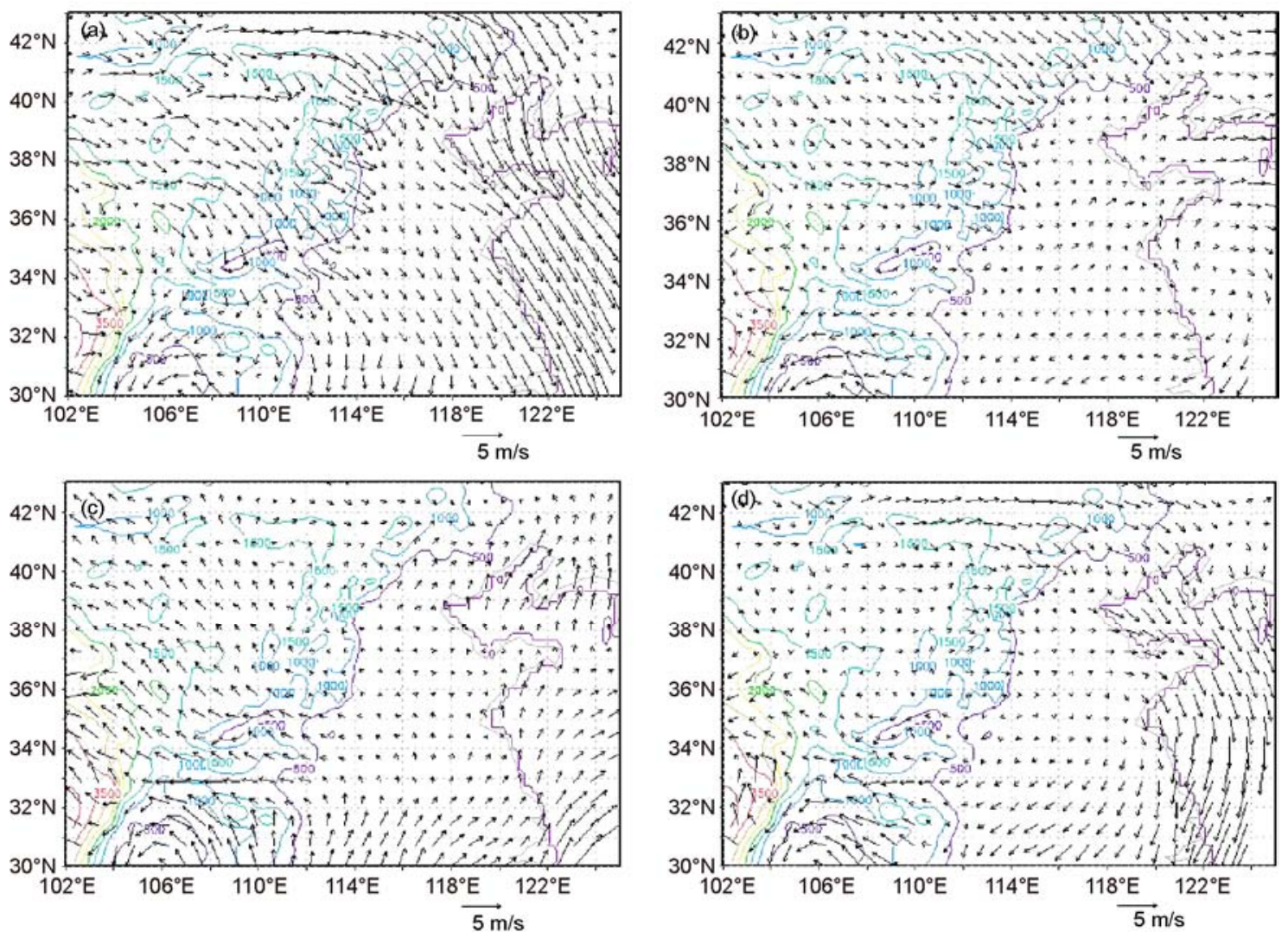

图 32007 年 ESTM 地区各季节代表月份近地面流场示意图

(a) 1 月; (b) 4 月; (c) 7 月; (d) 10 月

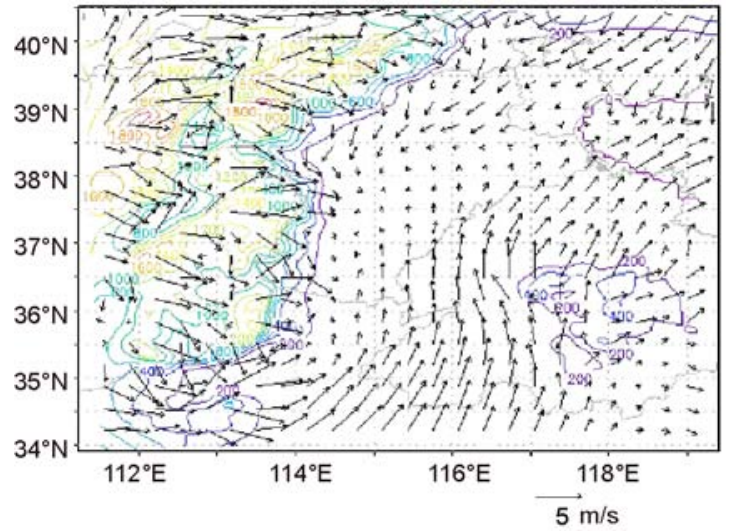

图 4 太行山东麓地区辐合风类型图

稳定的风场结构又加剧了空气污染物的积聚作用. 因此, OMI 监测仪可在该地区观测到较高的 $\mathrm{NO}_{2}$ 柱 浓度。

为了考察 $\mathrm{NO}_{2}$ 浓度水平高低与风场之间的对应 关系, 提取出一年中浓度最大值出现最为频繁的区 域 $\left(114^{\circ} \sim 115^{\circ} \mathrm{E}, 35^{\circ} \sim 39^{\circ} \mathrm{N}\right)$ 内每个网格所对应的 OMI
对流层 $\mathrm{NO}_{2}$ 柱浓度. 共 27 个网格, 选取 1 月作为重 污染冬季时段的代表月来进行分析研究.

冬季时段的主导风向为西北风(WN). MM5 模式 模拟结果表明，该地区西北风的风速十分强劲，有利 于大气污染物的扩散. 从图 5 可以看出, 在西北风控 制下, $\mathrm{NO}_{2}$ 浓度的日均值水平相对较低. 通过对 $\mathrm{NO}_{2}$ 柱浓度超过 $50 \times 10^{15} \mathrm{molec} / \mathrm{cm}^{2}$ 时风场类型的汇总发 现, $\mathrm{NO}_{2}$ 高浓度通常出现在以下情况: 静风、东北风 和辐合风场. 在静风和辐合风场影响下, 不利于大气 污染物的扩散稀释，污染物易发生积聚，从而导致 ESTM 地区 $\mathrm{NO}_{2}$ 浓度升高. 此外, 当主导风向为东北 风时, 特别是输送气流风速较大时, 可明显观察到从 北京-天津-唐山地区向下风向 ESTM 地区的长距离传 输影响.

\section{4 结论}

本研究采用 $\mathrm{OMI}$ 卫星观测的对流层 $\mathrm{NO}_{2}$ 柱浓度 数据和 MM5 气象场模拟分析研究了中国太行山东麓 


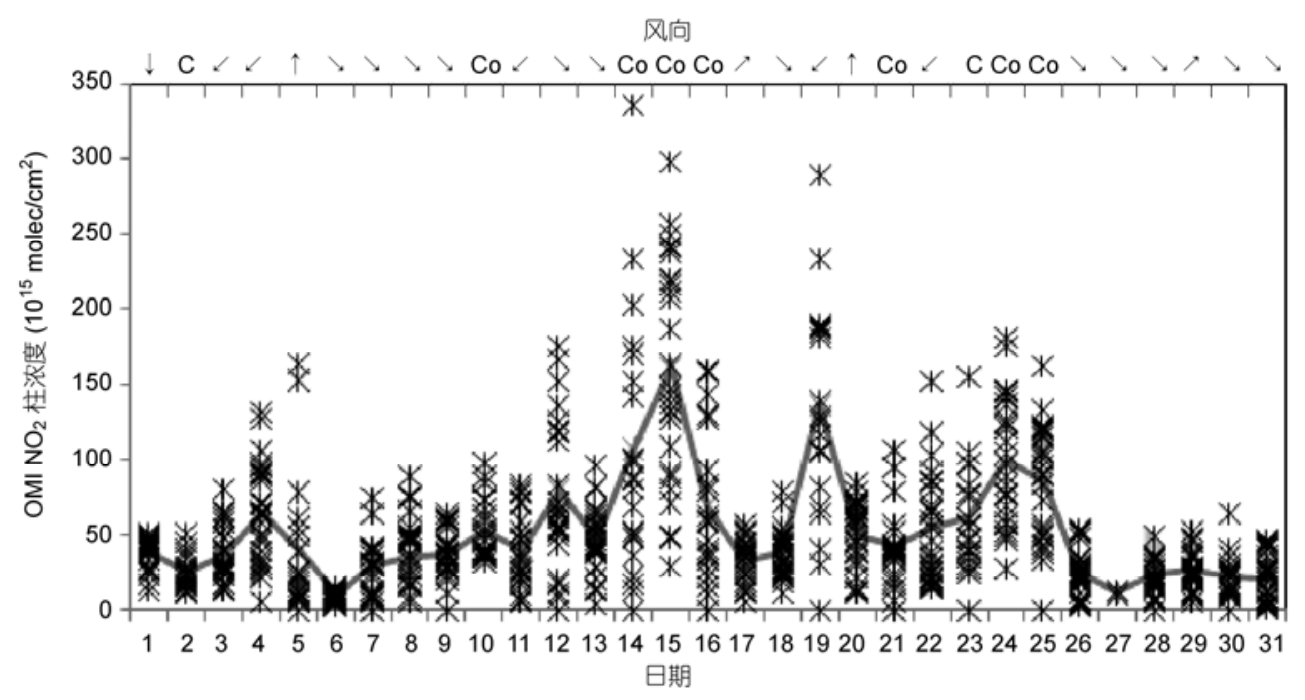

图 52007 年 1 月 $\mathrm{OMI}$ 对流层 $\mathrm{NO}_{2}$ 柱浓度日均值和风向的关系 $\left(114^{\circ} \sim 115^{\circ} \mathrm{E}, 3^{\circ} \sim 39^{\circ} \mathrm{N}\right)$

C 表示静风, Co 表示辐合风场

地区 $\mathrm{NO}_{X}$ 污染的季节变化特征及可能成因. $\mathrm{OMI}$ 监测 仪得到的对流层 $\mathrm{NO}_{2}$ 柱浓度数据对于地面 $\mathrm{NO}_{2}$ 浓度 的变化显示出了较高的灵敏性. $\mathrm{NO}_{2}$ 的最低值出现在 夏季, 最高值出现在冬季. MM5 的模拟和分析表明, 除了相对较高的人为源排放外, 太行山东麓地区 $\mathrm{NO}_{2}$ 高浓度还主要归因于不利的地形条件和区域大
气环流的影响. 静风和辐合风类型的频繁出现导致 了大气污染物的积聚, 进而造成污染恶化. 当东北风 为主导风向, 尤其是当输送气流风速较大时, $\mathrm{NO}_{X}$ 可 以从京津唐地区输送至下风向的太行山东麓地区. 研究结果表明, OMI 可用于区域大气污染的分析研究, 尤其是在缺少地面监测的情况下.

\section{参考文献} phys Res, 2007, 112, doi: 10.1029/2007JD008684

4 张懿华, 谢绍东. 基于临界负荷择选硫和氮沉降控制. 科学通报, 2009, 54: 1874-1879

5 陈罕立, 王金南. 关于我国 $\mathrm{NO}_{X}$ 排放控制的探讨. 环境科学研究, 2005, 18: 107-110

6 张兴赢, 张鹏, 张艳, 等. 近 $10 \mathrm{a}$ 中国对流层 $\mathrm{NO}_{2}$ 的变化趋势、时空分布特征及其来源解析. 中国科学 $\mathrm{D}$ 辑: 地球科学, 2007, 37: 1409-1416

7 周维, 王雪松, 张远航, 等. 我国 $\mathrm{NO}_{X}$ 污染状况与环境效应及综合控制策略. 北京大学学报(自然科学版), 2008, 44: 323-330

8 杨婷, 王自发, 张柏, 等. 基于激光雷达数据的奥运大气污染控制效果评估. 科学通报, 2010, 55: 931-936

9 Zhang Q, Streets D G, Carmichael G R, et al. Asian emissions in 2006 for the NASA INTEX-B mission. Atmos Chem Phys, 2009, 9: 5131-5153

10 Boersma K F, Eskes H J, Veefkind J P, et al. Near-real time retrieval of tropospheric $\mathrm{NO}_{2}$ from OMI. Atmos Chem Phys, 2007, 7: 2103-2118

11 张彦军, 牛铮, 王力, 等. 基于 $\mathrm{OMI}$ 卫星数据的城市对流层 $\mathrm{NO}_{2}$ 变化趋势研究. 地理与地理信息科学, 2008, 24: 96-99

12 王跃启, 江洪, 张秀英, 等. 基于 OMI 卫星遥感数据的中国对流层 $\mathrm{NO}_{2}$ 时空分布. 环境科学研究, 2009, 22: 932-937

13 Wang Y X, McElroy M B, Boersma K F, et al. Traffic restrictions associated with the Sino-African summit: Reductions of NO ${ }_{X}$ detected from space. Geophys Res Lett, 2007, 34, doi: 10.1029/2007GL029326

14 余环, 王普才, 宗雪梅, 等. 奥运期间北京地区卫星监测 $\mathrm{NO}_{2}$ 柱浓度的变化. 科学通报, 2009, 54: 299-304

15 Stavrakou T, Müller J F, Boersma F, et al. Assessing the distribution and growth rates of $\mathrm{NO}_{X}$ emission sources by inverting a 10 -year record of $\mathrm{NO}_{2}$ satellite columns. Geophys Res Lett, 2008, 35, doi: 10.1029/2008GL033521 
16 Lin J T, McElroy M B. Impacts of boundary layer mixing on pollutant vertical profiles in the lower troposphere: Implications to satellite remote sensing. Atmos Environ, 2010, 44: 1726-1739

17 Martin R V. Satellite remote sensing of surface air quality. Atmos Environ, 2008, 42: 7823-7843

18 Meng Z Y, Xu X B, Wang T, et al. Ambient sulfur dioxide, nitrogen dioxide, and ammonia at ten background and rural sites in China during 2007-2008. Atmos Environ, 2010, 44: 2625-2631

19 Celarier E A, Brinksma E J, Gleason J F, et al. Validation of Ozone Monitoring Instrument nitrogen dioxide columns. J Geophys Res, 2008, 113, doi: 10.1029/2007JD008908

20 Wenig M O, Cede A M, Bucsela E J, et al. Validation of OMI tro-pospheric $\mathrm{NO}_{2}$ column densities using direct-Sun mode Brewer measurements at NASA Goddard Space Flight Center. J Geophys Res, 2008, 113, doi: 10.1029/2007JD008988

21 Boersma K F, Jacob D J, Bucsela E J, et al. Validation of OMI tropospheric $\mathrm{NO}_{2}$ observations during INTEX-B and application to constrain $\mathrm{NO}_{X}$ emissions over the eastern United States and Mexico. Atmos Environ, 2008, 42: 4480-4497

22 Bucsela E J, Perring A E, Cohen R C, et al. Comparison of tropospheric $\mathrm{NO}_{2}$ from in situ aircraft measurements with near-real-time and standard product data from OMI. J Geophys Res, 2008, 113, doi: 10.1029/2007JD008838

23 程兴宏, 徐祥德, 丁国安. CMAQ 模式卫星产品源同化模型及其在空气质量预报中的应用研究. 中国科学 D 辑：地球科学, 2010, 40: $511-522$

24 Lamsal L N, Martin R V, van Donkelaar A, et al. Ground-level nitrogen dioxide concentrations inferred from the satellite-borne Ozone Monitoring Instrument. J Geophys Res, 2008, 113, doi: 10.1029/2007JD009235

25 Lamsal L N, Martin R V, van Donkelaar A, et al. Indirect validation of tropospheric nitrogen dioxide retrieved from the OMI satellite instrument: Insight into the seasonal variation of nitrogen oxides at northern midlatitudes. J Geophys Res, 2010, 115, doi: 10.1029/ 2009JD013351

26 Hao J M, Tian H Z, Lu Y Q. Emission inventories of $\mathrm{NO}_{X}$ from commercial energy consumption in China, 1995-1998. Environ Sci Technol, 2002, 36: 552-560

27 苗爱梅. 地形对太原市污染物稀释扩散影响的模拟试验. 气象学报, 2004, 62: 112-118

28 刘洁, 张小玲, 徐晓峰, 等. 北京地区 $\mathrm{SO}_{2}, \mathrm{NO}_{X}, \mathrm{O}_{3}$ 和 $\mathrm{PM}_{2.5}$ 变化特征的城郊对比分析. 环境科学, 2008, 29: 1059-1065 